\title{
HEATING AND MELTING OF ELECTRODES WITH EXOTHERMIC MIXTURE IN COATING
}

\author{
A.F. VLASOV, N.A. MAKARENKO and A.M. KUSHCHY \\ Donbas State Machine Building Academy \\ 72 Shkadinov Str., 84313, Kramatorsk, Donetsk region, Ukraine. E-mail: dgma@dgma.donetsk.ua
}

\begin{abstract}
It is a well known fact that introduction of exothermic mixtures in electrode coating composition can increase efficiency of manual arc welding. At that, distribution of heat between electrode and workpiece is not enough studied. This work studies thermal characteristics of heating and melting of the electrodes with different content of exothermic mixture in the coating. It is shown that introduction of the mixture in amount to $53.4 \mathrm{wt} \%$ results in rise of coefficient of core melting from 8.7 to $11.6 \mathrm{~g} /(\mathrm{A} \cdot \mathrm{h})$, weld deposition coefficient from 8.1 to $13 \mathrm{~g} /(\mathrm{A} \cdot \mathrm{h})$ as well as growth of efficiency of base metal heating. 10 Ref., 2 Tables. 1 Figure.
\end{abstract}

\begin{abstract}
$\boldsymbol{K} \boldsymbol{e} \boldsymbol{y} w \boldsymbol{w} \boldsymbol{d} \boldsymbol{s}:$ arc welding, coated electrodes, exothermic mixture, heating and melting of electrode, thermal characteristics
\end{abstract}

One of the main tasks for developers is increase of process efficiency and finding of new types of raw materials for manufacture of welding and surfacing consumables. One of the direction for solving of this problem can be utilization of effect of exothermic reactions at introduction of exothermic mixtures in form of corresponding oxidizers (dross, hematite, manganese ore) and deoxidizers (ferrotitanium, ferrosilicon, aluminum powder) in composition of the used materials [1-4]. Their heating provides for exothermic process resulting in melting of the electrode core. If quantity of iron oxides and element-deoxidizers is not enough in electrode coating, then the exothermic process takes place in a stage of droplet formation and transfer. Investigations performed [5] showed that change of content of exothermic mixture from 35 to $64 \%$ in the electrode coatings, consisting of dross and aluminum powder, promotes for increment of the temperature that makes $1280{ }^{\circ} \mathrm{C}$ and being enough for complete melting of the coating. However, distribution of heat between electrode and workpiece, emitted during exothermic reaction, is not sufficiently studied.

Aim of the present work is study of effect of quantity of exothermic mixture in the electrode coating on thermal characteristics of their melting.

The electrodes containing marble, fluorspar, rutile concentrate, ferromanganese, ferrotitanium, iron brass and aluminum powder in the coating were manufactured for the investigations. A coating mass factor was constant at core diameter $5 \mathrm{~mm}$ and different content of exother-

(c) A.F. VLASOV, N.A. MAKARENKO and A.M. KUSHCHY, 2014 mic mixture in the coating. Bead-on-plate welding using direct current of reversed polarity was carried out by these electrodes on plates of $10 \times$ $\times 80 \times 120 \mathrm{~mm}$ size with strip, preliminary installed over a heat-insulated rack. Welding converter PS-500 with ballast rheostats of RB-300 type was used as a power source. Deposition of each specimen was carried out during $20 \mathrm{~s}$. Time of electrode melting was determined using stopwatch, average value of welding current and arc voltage were defined according to recorders, and temperature of water heating was measured by

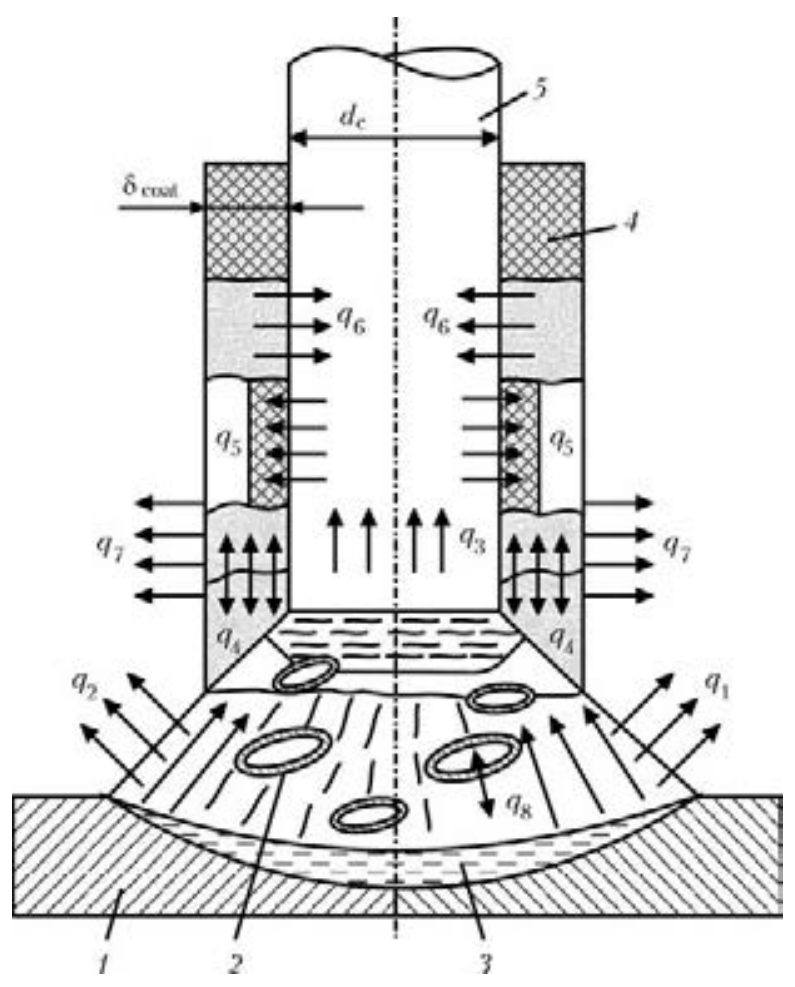

Model of heating and melting of electrode with exothermic mixture in coating: 1 - base metal; 2 - droplet of electrode metal; 3 - weld pool; 4 - coating; 5 - core (for designations see the text) 
thermometer with up to $0.05{ }^{\circ} \mathrm{C}$ accuracy. 3-5 measurements were carried out for each electrode composition.

The Figure shows that heat, emitted in metallic core of $d_{\mathrm{c}}$ diameter during electrode current heating, is consumed for rise of temperature of core $\left(q_{3}\right)$ and coating layer $\left(q_{5}\right)$ and transferred $\left(q_{7}\right)$ into ambient atmosphere through side surface. Heat flow of arc $q_{1}$, irradiation heat and heat of convective transfer $q_{2}$ have effect on the electrode tip. Temperature of $1000{ }^{\circ} \mathrm{C}$ (at content of more than $35 \%$ of exothermic mixture in the electrode coating) provides for the exothermic reaction with emission of heat $q_{4}$, one part of which is consumed for heating and melting of the coating $\left(q_{5}\right)$ and another is transferred to the electrode core $\left(q_{6}\right)$. Heat from convective heat transfer through electrode side surface to ambient atmosphere $\left(q_{7}\right)$ and heat, lost by drops of motel metal $\left(q_{8}\right)$, are important in this process.

Instantaneous heat balance

$$
Q=q_{1}+q_{2}+q_{3}+q_{4}+q_{5}+q_{6}+q_{7}+q_{8}
$$

or

$$
Q=q_{1}+q_{2}+q_{3}+q_{4}=q_{5}+q_{6}+q_{7}+q_{8} .
$$

Three sources heat the electrode. Firstly, it is a lumped source - welding arc, heat of which is introduced through heating spot at the electrode working tip $\left(q_{1}\right)$. Secondly, it is heat of irradiation and convective heat transfer $\left(q_{2}\right)$ and distributed on volume source - heat, emitted by electric current according to Joule-Lenz law along the whole length of electrode core from current-carrying contact to arc $\left(q_{3}\right)$. Thirdly, it is heat, emitted during exothermic reaction $\left(q_{4}\right)$.

Distribution of temperatures $T(x)$ in the electrode core was investigated during heating by power source at the tip depending on quantity of exothermic mixture in the electrode coating. Power source at the electrode tip can be considered as movable and traveling at electrode melting rate. Distribution of temperatures $T(x)$ in the electrode core during heating by source at the tip can be received using equation of limiting state of process of heat distribution from movable plane source in the core in area before source (at initial coefficient of thermal efficiency for core $b=0)$. The following equation is generated by inserting set values in known equation [6] at $x \geq$ $\geq 0$ and $t \rightarrow \infty$ :

$$
T-T_{\mathrm{c}}=\left(T_{\mathrm{d}}-T_{\mathrm{c}}\right) e_{w x / a},
$$

where $T_{\mathrm{c}}$ is the temperature of current heating of electrode core, ${ }^{\circ} \mathrm{C} ; x$ is the distance from tip of consumable electrode, temperature of tip of which equals average temperature of drops $T_{\mathrm{d}}$, $\mathrm{cm}$; $w$ is the rate of electrode melting, $\mathrm{cm} / \mathrm{s}$.

Temperature of drops, detaching from the consumable electrode, was determined on known formulae [7] considering data of work [8] according to average value of droplet enthalpy $(\Delta H=$ $=1850 \mathrm{~J} / \mathrm{g})$ in melting of Sv-08A wire and $I_{\mathrm{w}}=$ $=290 \mathrm{~A}$ (reversed polarity):

$$
\begin{aligned}
T_{\text {d.av }}=1798+(\Delta H-1330) / 0.92 & =1798+ \\
+520 / 0.92=565+1798=2326 \mathrm{~K} & =2090{ }^{\circ} \mathrm{C} .
\end{aligned}
$$

Table 1 gives the data characterizing effect of quantity of exothermic mixture in the electrode coating on temperature of section $x$ heated by arc at $T_{\mathrm{d}}=2100{ }^{\circ} \mathrm{C} ; T_{\mathrm{c}}=20{ }^{\circ} \mathrm{C} ; w=0.475-$ $0.645 \mathrm{~cm} / \mathrm{s} ; a=0.08 \mathrm{~cm}^{2} / \mathrm{s}$. Temperature of $1000{ }^{\circ} \mathrm{C}$, which promotes active exothermic reaction, is achieved at $1 \mathrm{~mm}$ distance from the electrode tip.

Temperature of heating [9] of coated electrode ET-2 of $5 \mathrm{~mm}$ diameter was determined in $60 \mathrm{~s}$ after beginning of arc burning at direct current 290 A. Initial electrode temperature $T_{0}=20{ }^{\circ} \mathrm{C}$. Calculation was carried out considering scientific recommendations [6] in the following way:

\begin{tabular}{|c|c|c|c|c|c|c|c|c|c|}
\hline \multirow{3}{*}{$\begin{array}{c}\text { Length of } \\
\text { section } x, \mathrm{~cm}\end{array}$} & \multicolumn{9}{|c|}{ Quantity of exothermic mixture $(\%)$ at $T\left({ }^{\circ} \mathrm{C}\right)$ and $w(\mathrm{~cm} / \mathrm{s})$} \\
\hline & 0 & 10.0 & 17.5 & 26.2 & 35.2 & 42.5 & 44.4 & 47.5 & 53.4 \\
\hline & 0.475 & 0.505 & 0.525 & 0.55 & 0.575 & 0.6 & 0.615 & 0.63 & 0.645 \\
\hline 0.09 & 1230 & 1190 & 1164 & 1131 & 1099 & 1069 & 1051 & 1034 & 1017 \\
\hline 0.1 & 1159 & 1117 & 1090 & 1056 & 1023 & 992 & 973 & 955 & 938 \\
\hline 0.2 & 640 & 595 & 565 & 531 & 499 & 469 & 451 & 435 & 419 \\
\hline 0.5 & 108 & 89.5 & 79 & 67.5 & 57.7 & 49.4 & 44.1 & 41 & 37.3 \\
\hline 1.0 & 5.6 & 3.8 & 2.97 & 2.3 & 1.6 & 1.2 & 0.96 & 0.8 & 0.7 \\
\hline
\end{tabular}

current density in the electrode

$$
j=\frac{4 I}{\pi d^{2}}=\frac{4 \cdot 290}{\pi \cdot 0.5^{2}}=14.8 \mathrm{~A} / \mathrm{mm}^{2},
$$

Table 1. Temperature of section $x$ of electrode heated by arc, and quantity of exothermic mixture in coating at different rate of electrode melting 
Table 2. Experimental and calculation values of characteristics of melting of electrodes with exothermic mixture in coating at $I_{\mathrm{w}}=$ $=290 \mathrm{~A}$

\begin{tabular}{|c|c|c|c|c|c|c|c|c|c|}
\hline \multirow{2}{*}{ Index } & \multicolumn{9}{|c|}{ Quantity of exothermic mixture, \% } \\
\hline & 0 & 10.5 & 17.5 & 26.2 & 35.2 & 42.5 & 44.4 & 47.5 & 53.4 \\
\hline$\alpha_{c . m}, g /(A \cdot h)$ & 8.7 & 9.4 & 9.7 & 10.2 & 10.4 & 10.9 & 11.2 & 11.4 & 11.6 \\
\hline$\alpha_{d}, g /(A \cdot h)$ & 8.1 & 9.1 & 9.7 & 10 & 10.9 & 11.4 & 12 & 12.2 & 13 \\
\hline$U_{\mathrm{a}}, \mathrm{V}$ & 25 & 25.7 & 26 & 26.5 & 27 & 27.3 & 27.5 & 27.7 & 28 \\
\hline$Q_{\mathrm{a}}, \mathrm{J} / \mathrm{s}$ & 7250 & 7453 & 7540 & 7685 & 7830 & 7917 & 7975 & 8033 & 8120 \\
\hline$Q_{\text {chem }}, \mathrm{J} / \mathrm{s}$ & 0 & 45.2 & 138.7 & 274.6 & 442.5 & 619.5 & 701.6 & 777.3 & 926.5 \\
\hline$w, \mathrm{~cm} / \mathrm{s}$ & 0.475 & 0.52 & 0.525 & 0.55 & 0.58 & 0.6 & 0.615 & 0.63 & 0.645 \\
\hline$v_{\text {coat.m }}, \mathrm{g} / \mathrm{s}$ & 0.40 & 0.42 & 0.44 & 0.47 & 0.50 & 0.54 & 0.56 & 0.58 & 0.59 \\
\hline$Q_{\mathrm{h}}, \mathrm{J} / \mathrm{s}$ & 5220 & 5610 & 5716 & 6046 & 6405 & 6700 & 6886 & 7090 & 7373 \\
\hline$m_{\mathrm{sl}}, \mathrm{g}$ & 7.5 & 7.43 & 7.37 & 7.3 & 6.7 & 6.4 & 6.2 & 6.3 & 6.3 \\
\hline$m_{c}, \mathrm{~g}$ & 14 & 15 & 15.8 & 16.7 & 17.1 & 18.5 & 19.2 & 19.6 & 20 \\
\hline$m_{\mathrm{d} . \mathrm{m}}, \mathrm{g}$ & 10.5 & 12.1 & 13.5 & 15 & 17.5 & 18.5 & 19.5 & 20 & 20.8 \\
\hline$\eta_{\mathrm{e}}$ & 0.28 & 0.3 & 0.315 & 0.34 & 0.365 & 0.385 & 0.392 & 0.405 & 0.415 \\
\hline$\eta_{\mathrm{b}, \mathrm{m}}$ & 0.715 & 0.735 & 0.745 & 0.76 & 0.773 & 0.79 & 0.795 & 0.805 & 0.815 \\
\hline$Q_{\mathrm{e}}, \mathrm{J} / \mathrm{s}$ & 2030 & 2236 & 2375 & 2613 & 2858 & 3048 & 3126 & 3253 & 3370 \\
\hline
\end{tabular}

where $I$ is the welding current, A; $d$ is the core diameter, $\mathrm{cm}$;

coefficients

$$
\begin{aligned}
w_{0}= & 2.4 \cdot 10^{-2} j^{2}=2.4 \cdot 10^{-2} \cdot 14.8^{2}=5.26 \mathrm{deg} / \mathrm{s} \\
b_{0}= & \frac{0.96 \cdot 10^{-2}}{d}=\frac{0.96 \cdot 10^{-2}}{5}=0.192 \cdot 10^{-2} 1 / \mathrm{deg} ; \\
& n t=\left[5 \cdot 10^{-3} \cdot 5.26+\right. \\
& \left.+0.192 \cdot 10^{-2}\left(1+5 \cdot 10^{-3} \cdot 20\right)\right] \cdot 60=1.68 ; \\
& \quad 3\left(\omega_{0} / b_{0}+T_{0}\right)= \\
& \left.5 \cdot 10^{-3}\left(5.26 / 0.192 \cdot 10^{-2}\right)+20\right)=13.8
\end{aligned}
$$

According to known nomogram [6] coefficient $\beta T=3.5$ and coefficient $\beta=5 \cdot 10^{-3} 1 / \mathrm{deg}$. In that case maximum temperature of heating of studied electrodes using optimum current makes $T=3.5 / 5 \cdot 10^{-3}=700{ }^{\circ} \mathrm{C}$.

Thermal effect of the exothermic reaction due to interaction of element-deoxidizers with iron oxide was determined on known equation [10]

$$
Q_{\text {chem }}=\sum_{i=1}^{i=k} \frac{G_{\mathrm{m} . \mathrm{c}}}{t} K_{m} \frac{Q_{i \text { ex.m }}}{100} q_{i \text { ex.m }},
$$

where $G_{\text {m.c }}$ is the quantity of molten core, $\mathrm{g} ; K_{m}$ is the coating mass factor; $Q_{i \text { ex.m }}$ is the quantity of exothermic mixture in electrode coating at interaction of $i$-th element-deoxidizer ( $\mathrm{Al}, \mathrm{Ti}, \mathrm{Si}$, $\mathrm{Mn}$ ) with iron oxide, $\%$; $q_{i \text { ex.m }}$ is thermal effect of exothermic mixture at interaction of $1 \%$ of ferrous oxide with element-deoxidizers, $\mathrm{J} / \mathrm{s}$.
Table 2 gives the indices of effect of quantity of exothermic mixture in the electrode coating on characteristics of their melting.

The results received showed that introduction of exothermic mixture in the electrode coating rises quantity of molten core in the ranges of 14-20 $\mathrm{g}$ and coating from 8 to $11.8 \mathrm{~g}$ at constant coating mass factor. It takes place mainly due to heat emitted during exothermic reaction, and reduction of heat consumed for coating melting due to corresponding reduction of gas-slag-forming section of the coating and rise of metallic constituent. Introduction of up to $53.4 \%$ of exothermic mixture in the coating composition varies electrode heating coefficient from 0.280 to 0.415 , at that, variation has directly proportional nature. Increase of quantity of deposited metal in the ranges of 10.5-20.8 $\mathrm{g}$ at almost similar quantity of slag on the plate shows that additional heating of the plate takes place mainly due to increase of quantity of electrode metal being transferred in the same time. The electrode with exothermic mixture in the coating can be used with maximum efficiency in welding and surfacing works, performance of which requires preliminary and concurrent heating and delayed cooling.

\section{Conclusions}

1. Introduction of up to $53.4 \%$ of exothermic mixture in the electrode coating rises coefficient of core melting $\left(\alpha_{c . m}=8.7-11.6 \mathrm{~g} /(\mathrm{A} \cdot \mathrm{h})\right)$ and deposition $\left(\alpha_{d}=8.1-13.0 \mathrm{~g} /(\mathrm{A} \cdot \mathrm{h})\right)$, effective 
efficiency of heating of base metal $\left(\eta_{\mathrm{b} m}=0.715^{-}\right.$ $0.815)$ and electrode $\left(\eta_{\mathrm{e}}=0.280-0.415\right)$.

2. Introduction of exothermic mixture in the electrode coating increases rate of electrode melting due to rise of thermal power of arc; heat emitted during exothermic reaction; reduction of heat consumption for melting of gas-slag-forming section of the coating; improvement of technological properties of arc.

3. It is determined that maximum temperature of heating of the studied electrodes by passing optimum current makes $700{ }^{\circ} \mathrm{C}$.

4. Temperature of $1000^{\circ} \mathrm{C}$, which makes exothermic reaction efficient, was received at around $1 \mathrm{~mm}$ distance from the electrode tip.

1. Karpenko, V.M., Vlasov, A.F., Bilyk, G.B. (1980) Factors of welding electrode melting with exothermic mixture in coating. Svarochn. Proizvodstvo, 9, 2325

2. Ioffe, I.S. (1980) Effect of titanium thermal mixture in electrode coating on increase of welding efficiency. Ibid., 3, 26-28.
3. Zarechensky, A.V. (1985) Peculiarities of melting of flux-cored strips with thermit mixtures. Ibid., 8, 3941.

4. Chigarev, V.V., Zarechensky, D.A., Belik, A.G. (2007) Peculiarities of melting of flux-cored strips with exothermic mixtures contained in their filler. The Paton Welding J., 2, 46-48.

5. Vlasov, A.F., Karpenko, V.M., Leshchenko, A.I. (2006) Experimental definition of exothermic process proceeding in heating and melting of electrodes. Visnyk DDMA, 4(2), 65-68.

6. (1970) Theoretical principles of welding. Ed. by V.V. Frolov. Moscow: Vysshaya Shkola.

7. Ando, K., Nishiguchi, K. Mechanism of formation of pencil point-like wire tip in MIG welding. II W Doc. 212-156-68-69.

8. Erokhin, A.A. (1973) Principles of fusion welding. Moscow: Mashinostroenie.

9. Vlasov, A.F., Oparin, Yu.N., Belaya, V.M. et al. Composition of electrode coating. USSR author's cert. 737175. Int. Cl. B 23K, 35 36. Fil. 10.11.77. Publ. 30.05.80.

10. Vlasov, A.F., Kushchy, A.M. (2011) Technological characteristics of electrodes with exothermic mixture in coating for surfacing of tool steels. Svarochn. Proizvodstvo, 4, 10-15.

Received 16.04.2014 